Pacific Journal of Mathematics

KELLY AND RADON-TYPE THEOREMS IN INTERVAL
CONVEXITY SPACES 


\title{
HELLY AND RADON-TYPE THEOREMS IN INTERVAL CONVEXITY SPACES
}

\author{
PhILLIP W. BeAN
}

The notion of interval convexity $T$ on a point set $S$ is defined. If $T$ is an interval convexity defined on $S, \mathscr{C}(T)$ will denote the collection of nonempty $T$-convex subsets of $S$. Properties $k, H(k)$ (a Helly property), and $R(k, n)$ (a Radon property) are defined on $\mathscr{C}(T)$, and relationships between these properties are investigated.

A partial order convexity $\leqq$ on a point set $S$ is a special type of interval convexity. Some sufficient conditions are imposed on $\leqq$ and $\mathscr{C}(\leqq)$ to insure the existence of certain Radon-type properties.

1. Introduction. Suppose $S$ is a point set, and $\mathscr{P}(S)$ is the collection of nonempty subsets of $S$. The statement that $T$ is an interval convexity on $S$ means that $T$ is a transformation from $S \times$ $S$ into $\mathscr{P}(S)$. A subset $M$ of $S$ is said to be $T$-convex provided that $T(x, y)$ is a subset of $M$ for every $x$ and $y$ in $M$. Let $\mathscr{C}(T)$ denote the collection of all nonempty $T$-convex subsets of $S$. For each $M \epsilon$ $\mathscr{P}(S)$, the convex hull of $M$ relative to $T$, denoted by Co $(M)$, is the intersection of the elements of $\mathscr{C}(T)$ which contain $M$. We assume that if each of $x$ and $y$ is in $S$, then $T(x, y)$ is T-convex, $T(x, y)$ contains $x$ and $y$, and $T(x, y)=T(y, x)$.

Let $m$-set mean a set of $m$ points of $S$. A subset $M$ of $S$ is said to be $n$-divisible provided it may be partitioned into $n$ mutually exclusive subsets whose $T$-convex hulls have a common point of $S$. In this paper we consider the relationship of the following Helly and Radon-type properties on a set $S$ with an interval convexity $T . \quad \mathscr{C}(T)$ has property $R(k)$ if each $(k+1)$-set of $S$ is 2-divisible, and more generally, $\mathscr{C}(T)$ has property $R(k, n)$ with respect to some integer valued function $f$ if each $[f(k, n)]$-set is $n$-divisible. We say that $\mathscr{C}(T)$ has property $r(k)$ if $k$ is the smallest integer for which $\mathscr{C}(T)$ has property $R(k) . \mathscr{C}(T)$ is said to have property $H(k)$ provided that if $\mathscr{G}$ is a finite subcollection of $\mathscr{C}(T)$ containing at least $k$ elements, then the following two statements are equivalent:

(a) Each $k$ elements of $\mathscr{G}$ have a common point.

(b) The elements of $\mathscr{G}$ have a common point.

In (2) we give sufficient conditions for property $R(k)$ to be equivalent to property $H(k)$. We also consider in (2) the existence of sets with property $R(k)$ in partially ordered spaces and more generally, in (3) the existence of sets with property $R(k, n)$. 
2. Theorems concerning properties $k, R(k)$, and $H(k)$. From a theorem of Levi [7] we have that property $R(k)$ implies property $H(k)$. In [1] Calder introduces the following property: $\mathscr{C}(T)$ has property $k$ provided that if $M$ is a finite point set containing at least $k+1$ points, then there exists a point $p$ such that $p \in \operatorname{Co}[M \sim\{m\}]$ for each $m$ in $M$. He proves that property $k$ is equivalent to property $H(k)$ and then proves that property $R(k)$ is equivalent to property $H(k)$ in a partially ordered space. It should be noted that the partial order does not have to be antisymmetric. Calder also gives an example of an interval convexity $T$ such that property $H(k)$ is not equivalent to property $R(k)$ in $\mathscr{C}(T)$. In the first two theorems of this section we give sufficient conditions on $T$ for properties $H(k)$ and $R(k)$ to be equivalent.

If each of $A$ and $B$ is in $\mathscr{P}(S)$, then $A * B$ denotes the set

$$
\bigcup_{a \in A, b \in B} T(a, b) \text {. }
$$

THEOREM 2.1. Let $T$ be an interval convexity on $S$ such that for each $M$ in $\mathscr{P}(S)$, Co $(M)=M * M$; and if $a, b, c$, and $d$ are four distinct points such that $d$ is in $T(a, b)$ and $T(\alpha, c)$, then $b$ is in $T(a, c)$, or $c$ is in $T(\alpha, b)$. Then property $H(k) \Leftrightarrow$ property $R(k)$ in $\mathscr{C}(T)$.

THEOREM 2.2. Let $T$ be an interval convexity on $S$ such that for each $M$ in $\mathscr{P}(S)$, Co $(M)=\bigcup_{m \in M} T(m, m)$. Then property $H(k) \Leftrightarrow$ property $R(k)$ in $\mathscr{C}(T)$.

The proofs of Theorems 2.1 and 2.2 are easy modifications of the proof of Theorem 3.2 of Calder [1].

Example 2.1. Let $M$ be a subset of a linear space $S$. A subset $K$ of $M$ is said to be extremal provided that if $k$ is an element of $K$, and there exist elements $x$ and $y$ in $M$ such that $k=t x+(1-$ t) $y$ for some $t \in(0,1)$, then $x$ and $y$ are elements of $K$. Obviously, the union and intersection of any collection of extremal subsets of $M$ are extremal.

We define an interval convexity $T$ on $M$ as follows: If each of $x$ and $y$ is an element of $M, T(x, y)$ is the intersection of the extremal subsets of $M$ which contain $\{x, y\}$.

For each subset $K$ of $M, K \subset \bigcup_{k \in K} T(k, k)$. Since $\bigcup_{k \in K} T(k, k)$ is convex, $\mathrm{Co}(K) \subset \bigcup_{k \in K} T(k, k)$. However, $\bigcup_{k \in K} T(k, k) \subset \mathrm{Co}(K)$. Thus Co $(K)=\bigcup_{k \in K} T(k, k)$, and hence property $H(k) \Leftrightarrow$ property $R(k)$ in $\mathscr{C}(T)$.

Let $\leqq$ be a partial order on the set $S$. If each of $x$ and $y$ is a point of $S,[x, y]=\{p \mid p=s$, or $p=y$, or $x<p<y$, or $y<p<x\}$. 
A subset $M$ of $S$ is said to be $\leqq-c o n v e x$ if for all elements $x$ and $y$ of $M,[x, y]$ is a subset of $M$. The collection of all $\leqq$-convex subsets of $S$ is denoted by $\mathscr{C}(\leqq)$. In [5], Franklin shows that Co $(M)=$ $M * M$ for any $M$ in $\mathscr{P}(S)$.

THEOREM 2.3. Suppose $\leqq i s$ a partial order on $S$, and $S$ is the union of $n$ linearly ordered sets, $S_{1}, S_{2}, \cdots, S_{n}$. Then $\mathscr{C}(\leqq)$ has property $R(2 n)$.

Proof. Suppose $M=\left\{x_{1}, x_{2}, \cdots, x_{2 n+1}\right\}$ is a $(2 n+1)$-set. Then for some $i, 1 \leqq i \leqq n, S_{i}$ contains at least three points, $z_{1}, z_{2}, z_{3}$, of $M$ such that $z_{1}<z_{2}<z_{3}$. Thus Co $\left\{z_{2}\right\}$ and Co $\left\{z_{1}, z_{3}\right\}$ have a common point, and therefore $\mathscr{C}(\leqq)$ has property $R(2 n)$.

It is easy to show that $\mathscr{C}(\leqq)$ has property $r(2)$ if and only if $\leqq$ linearly orders $S$. Suppose $\leqq$ is a partial order on $S$ which does not linearly order $S$. Under these conditions on $\leqq$, does $\mathscr{C}(\leqq)$ have property $r(3)$ if and only if $S$ is union of two mutually exclusive, linearly ordered subsets $S_{1}$ and $S_{2}$ ? The following example shows the answer to this question is no.

ExAMPLE 2.2. Let $S=\left\{(x, y) \in R^{2} \mid y=0\right.$ or $\left.y=1\right\}$. Define $\leqq$ on $S$ as follows: $\left(x_{1}, y_{1}\right) \leqq\left(x_{2}, y_{2}\right)$ if $y_{1}=y_{2}$ and $x_{1} \leqq x_{2}$. Thus $\leqq$ is a partial order on $S$ which does not linearly order $S$. However, $\leqq$ does linearly order $S_{1}=\left\{(x, 1) \in R^{2}\right\}$ and $S_{2}=\left\{(x, 0) \in R^{2}\right\}$, and $S=$ $S_{1} \cup S_{2}$. To show that $\mathscr{C}(\leqq)$ does not have property $r(3)$ we choose $M=\{(0,0),(1,0),(0,1),(1,1)\}$. Obviously $M$ is not 2-divisible.

3. Property $R(k, n)$. Tverberg shows in [11] that the collection on convex sets in $R^{k-1}$ has property $R(k, n)$ with respect to $f(k, n)=$ $(n-1) k+1$ for $n, k \geqq 2$. By putting suitable restrictions on $T$, we have the following:

THEOREM 3.1. Suppose $T$ is an interval convexity on $S$ such that if $M \in \mathscr{P}(S)$, then $\mathrm{Co}(M)=\bigcup_{m \in M} T(m, m)$. If $\mathscr{C}(T)$ has property $R(k)$, then $\mathscr{C}(T)$ has property $R(k, n)$ with respect to $f(k, n)=(n-$ 1)k +1 . for $n \geqq 2$.

Proof. (We use induction on n.) Suppose $\mathscr{C}(T)$ has property $R(k)$, i.e., $\mathscr{C}(T)$ has property $R(k, 2)$. Suppose further that $\mathscr{C}(T)$ has property $R(k, m)$ for some $m \geqq 2$, and let $M=\left\{x_{1}, x_{2}, \cdots, x_{m k+1}\right\}$ be an $[m k+1]$-set. Let $M_{1}=\left\{x_{1}, x_{2}, \cdots, x_{(m-1) k+1}\right\}$ be the subset of $M$ containing the first $(m-1) k+1$ points of $M$. Then there exist $m$ points, $y_{11}, y_{12}, \cdots, y_{1 m}$, of $M_{1}$ and a point $p_{1}$ such that 


$$
p_{1} \in \bigcap_{i=1}^{m} \operatorname{Co}\left\{y_{1 i}\right\} .
$$

Now choose $M_{2}=\left\{x_{1}, x_{2}, \cdots, x_{(m-1) k+1}, x_{(m-1) k+2}\right\} \sim\left\{y_{11}\right\}$. Thus $M_{2}$ is an $[(m-1) k+1]$-set, and hence there exist $m$ points, $y_{21}, y_{22}, \cdots, y_{2 m}$, of $M_{2}$ and a point $p_{2} \in \bigcap_{i=1}^{m}$ Co $\left\{y_{2 i}\right\}$.

Continuing this process we get $M_{j}=\left[M_{j-1} \cup\left\{x_{(m-1) k+j}\right\}\right] \sim\left\{y_{j-11}\right\}$ for $3 \leqq j \leqq k+1$, and each of the sets is an $[(m-1) k+1]$-set. Thus there exist $m$ points, $y_{j 1}, y_{j 2}, \cdots, y_{j m}$, of $M_{j}$ and a point $p_{j} \in \bigcap_{i=1}^{m} \operatorname{Co}\left\{y_{j i}\right\}$.

Let $K=\left\{p_{1}, p_{2}, \cdots, p_{k+1}\right\}$. If $p_{i}=p_{j}$ for some $i \neq j$, the theorem is proved. Suppose $p_{i} \neq p_{j}$ if $i \neq j$. Since $\mathscr{C}(T)$ has property $R(k)$, there exist points, $p_{i}$ and $p_{j}, i<j$, in $K$ and a point

$$
p_{0} \in \operatorname{Co}\left\{p_{i}\right\} \cap \operatorname{Co}\left\{p_{j}\right\} \text {. }
$$

Since for each $x \in S, T(x, x)$ is convex, we have $p_{0} \in \operatorname{Co}\left\{y_{i 1}\right\} \cap \operatorname{Co}\left\{y_{j_{1}}\right\} \cap$ ... $\cap$ Co $\left\{y_{j m}\right\}$. Thus $M$ is $(m+1)$-divisible and $\mathscr{C}(T)$ has property $R(k$, $m+1)$. Therefore, $\mathscr{C}(T)$ has property $R(k, n)$ with respect to $f(k$, $n)=(n-1) k+1$ for all $n \geqq 2$.

ExAmple 3.1. In $R^{2}$ let $l / P$ and $\overline{l / P}$ denote, respectively, the open and the closed half planes determined by the line $l$ and containing the point $P . \quad P Q$ denotes the line determined by the points $P$ and $Q$, and $P[m]$ denotes the line through $P$ with slope $m$. Let $P_{0}=(0,0), P_{1}=(1,0), P_{2}=(-1 / 2, \sqrt{3} / 2), P_{3}=(-1 / 2,-\sqrt{3 / 2}), P_{4}=(1,1)$, $P_{5}=(-1,0), P_{6}=(1,-1)$. Choose $S=S_{1} \cup S_{2} \cup S_{3}$ where $S_{1}=P_{0} P_{1} / P_{4} \cap$ $P_{0} P_{2} / P_{4}, S_{2}=P_{0} P_{2} / P_{5}^{\prime} \cap P_{0} P_{3} / P_{5}$, and $S_{3}=P_{0} P_{1} / P_{6} \cap P_{0} P_{3} / P_{6}$ We define an interval convexity $T$ on $S$ as follows:

$$
\begin{aligned}
& \text { (a) } T(P, P)=\left\{\begin{array}{l}
S_{1} \cap \overline{P[-\sqrt{3}] / P_{0}} \text { if } P \in S_{1} \\
S_{2} \cap \overline{P[\sqrt{3}] / P_{0}} \text { if } \quad P \in S_{2} \\
S_{3} \cap \overline{P[0] / P_{0}} \text { if } P \in S_{3} .
\end{array}\right. \\
& \text { (b) } T(P, Q)=T(P, P) \cup T(Q, Q) .
\end{aligned}
$$

Thus if $M \in \mathscr{P}(S)$, Co $(M)=\bigcup_{m \in M} T(m, m)$. It is easily seen that $\mathscr{C}(T)$ has property $r(3)$. Thus if $k \geqq 3, \mathscr{C}(T)$ has property $R(k, n)$ with respect to $f(k, n)=(n-1) k+1$ for $n \geqq 2$.

THEOREM 3.2. Suppose $\leqq i$ is a partial order on $S$ such that $\mathscr{C}(\leqq)$ has property $R(k)$. Then $\mathscr{C}(\leqq)$ has property $R(k, n)$ with respect to $f(k, n)=(2 n-3) k+1$ for all $n \geqq 2$.

Proof. (The proof is a slight modification of the proof of Theorem 3.1.) The statement is true for $n=2$ since property $R(k)$ is the same as property $R(k, 2)$. Now suppose the statement is true for 
$n=m$, and let $M=\left\{x_{1}, x_{2}, \cdots, x_{(2 m-3) k+1}, \cdots, x_{(2 m-1) k+1}\right\}$ be a $[(2 m-1) k+$ 1]-set. (Note that $[(2 m-1) k+1]-[(2 m-3) k+1]=2 k$.) Let $K_{0}=$ $\left\{x_{1}, x_{2}, \cdots, x_{(2 m-3) k+1}\right\}$ be the subset of $M$ containing the first $(2 m-$ $3) k+1$ points of $M$. Thus there exist $m$ mutually exclusive subsets, $K_{01}, K_{02}, \cdots, K_{0 m}$, of $K_{0}$ and a point $y_{0} \in \bigcap_{i=1}^{m} \operatorname{Co}\left(K_{0 i}\right)$. It follows then that there exist points $s_{0}$ and $t_{0}$ in $K_{0}$ such that $s_{0}<y_{0}<t_{0}$. Now let $K_{1}$ be the $[(2 m-3) k+1]$-set $\left[K_{0} \sim\left\{s_{0}, t_{0}\right\}\right] \cup\left\{x_{(2 m-3) k+2}, x_{(2 m-3) k+3}\right\}$. Again there exist $m$ mutually exclusive subsets, $K_{11}, K_{12}, \cdots, K_{1 m}$, of $K_{1}$ such that $\bigcap_{i=1}^{m} \operatorname{Co}\left(K_{1 i}\right) \neq \varnothing$. If $y_{0} \in \bigcap_{i=1}^{m}$ Co $\left(K_{1 i}\right)$, the theorem is proved.

Suppose $y_{0} \notin \bigcap_{i=1}^{m} \operatorname{Co}\left(K_{1 i}\right)$. Let $y_{1} \in \bigcap_{i=1}^{m} \operatorname{Co}\left(K_{1 i}\right)$. Then there exist points $s_{1}$ and $t_{1}$ in $K_{1}$ such that $s_{1}<y_{1}<t_{1}$.

Continuing this process for $2 \leqq i \leqq k$, we obtain $K_{i}=\left[K_{i-1} \sim\right.$ $\left.\left\{s_{i-1}, t_{i-1}\right\}\right] \cup\left\{x_{(2 m-3) k+2 i}, x_{(2 m-3) k+(2 i+1)}\right\}$ and correspondingly $m$ mutually exclusive subsets, $K_{\imath 1}, K_{\imath 2}, \cdots, K_{i m}$, of $K_{i}$ such that $\bigcap_{p=1}^{m} \operatorname{Co}\left(K_{i p}\right)$ contains a point $y_{2}$. Now if for some $j$ and $i, 0 \leqq j<i \leqq k, y_{j} \epsilon$ $\bigcap_{p=1}^{m}$ Co $\left(K_{i p}\right)$, the theorem is proved.

Suppose that if $0 \leqq j<i \leqq k, y_{j} \notin \bigcap_{p=1}^{m} \operatorname{Co}\left(K_{i p}\right)$. Then the $(k+$ 1)-set $C=\left\{y_{0}, y_{1}, \cdots, y_{k}\right\}$ is 2-divisible. Let $C_{1}$ and $C_{2}$ be mutually exclusive subsets of $C$ such that $\operatorname{Co}\left(C_{1}\right) \cap \operatorname{Co}\left(C_{2}\right) \neq \varnothing$. It can be shown that if $w \in \mathrm{Co}\left(C_{1}\right) \cap \mathrm{Co}\left(C_{2}\right)$ then there are $m+1$ mutually exclusive subsets, $M_{1}, M_{2}, \cdots, M_{m+1}$, of $M$ such that $w \in \bigcap_{i=1}^{m+1} \operatorname{Co}\left(M_{i}\right)$. Hence $M$ is $m+1$ divisible. Therefore, $\mathscr{C}(\leqq)$ has property $R(k, n)$ with respect to $f(k, n)=(2 n-3) k+1$ for all $n \geqq 2$.

\section{REFERENCES}

1. J. R. Calder, Some elementary properties of interval convexities, J. London Math. Soc., 3 (1971), 422-428.

2. L. Danzer, N. Grümbaum, and V. Klee, Helly's theorem and its relatives, Proceedings of Symposia in Pure Mathematics, 7 (1963), Convexity, 101-177.

3. J. Eckhoff, Der Satz von Radon in honvexen Productstrukturen $I-I I$, Monatsh. Math., 72 (1968), 303-314, and 73 (1969), 7-30.

4. J. W. Ellis, A general set-separation theorem, Duke Math. J., 19 (1952), 417-421.

5. S. P. Franklin, Some results on order convexity, Amer. Math. Monthly, 69 (1962), 357-359.

6. David Kay and E. W. Womble, Axiomatic convexity theory and relationships between the Caratheordory, Helly and Radon numbers, Pacific J. Math., 38 (1971), 471-485.

7. F. W. Levi, On Helly's theorem and the axioms of convexity, J. Indian Mathematical Society, (N. S.) Part A, 15 (1951), 65-76.

8. T. S. Motzkin, Linear Inequalities, Mimeographed lecture notes, University of California, Los Angeles, 1951.

9. J. R. Reay, Caratheordory theorems in convex product structure, Pacific J. Math., 35 (1970), 227-230.

10. - An extension of Radon's theorem, Illinois J. Math., 12 (1968), 184-189. 
11. H. Tverberg, A generalization of Radon's theorem, J. London Math. Soc., 41 (1966), 123-128.

Received February 13, 1973 and in revised form November 11, 1973.

MERCER UNIVERSITY 


\section{PACIFIC JOURNAL OF MATHEMATICS}

\section{EDITORS}

RICHARD ARENS (Managing Editor)

University of California

Los Angeles, California 90024
J. DUGUNDJI*

Department of Mathematics

University of Southern California

Los Angeles, California 90007

D. Gilbarg and J. Milgram

Stanford University

Stanford, California 94305
University of Washington

Seattle, Washington 98105

ASSOCIATE EDITORS
E. F. BECKENBACH
B. H. NeumanN
F. WoLF
K. YosHIDA

\section{SUPPORTING INSTITUTIONS}

\author{
UNIVERSITY OF BRITISH COLUMBIA \\ CALIFORNIA INSTITUTE OF TECHNOLOGY \\ UNIVERSITY OF CALIFORNIA \\ MONTANA STATE UNIVERSITY \\ UNIVERSITY OF NEVADA \\ NEW MEXICO STATE UNIVERSITY \\ OREGON STATE UNIVERSITY \\ UNIVERSITY OF OREGON \\ OSAKA UNIVERSITY
}

\author{
UNIVERSITY OF SOUTHERN CALIFORNIA \\ STANFORD UNIVERSITY \\ UNIVERSITY OF TOKYO \\ UNIVERSITY OF UTAH \\ WASHINGTON STATE UNIVERSITY \\ UNIVERSITY OF WASHINGTON
* * * *
AMERICAN MATHEMATICAL SOCIETY \\ NAVAL WEAPONS CENTER
}

The Supporting Institutions listed above contribute to the cost of publication of this Journal, but they are not owners or publishers and have no responsibility for its content or policies.

Mathematical papers intended for publication in the Pacific Journal of Mathematics should be in typed form or offset-reproduced, (not dittoed), double spaced with large margins. Underline Greek letters in red, German in green, and script in blue. The first paragraph or two must be capable of being used separately as a synopsis of the entire paper. Items of the bibliography should not be cited there unless absolutely necessary, in which case they must be identified by author and Journal, rather than by item number. Manuscripts, in duplicate if possible, may be sent to any one of the four editors. Please classify according to the scheme of Math. Rev. Index to Vol. 39. All other communications to the editors should be addressed to the managing editor, or Elaine Barth, University of California, Los Angeles, California, 90024.

100 reprints are provided free for each article, only if page charges have been substantially paid. Additional copies may be obtained at cost in multiples of 50 .

The Pacific of Journal Mathematics is issued monthly as of January 1966. Regular subscription rate: $\$ 72.00$ a year (6 Vols., 12 issues). Special rate: $\$ 36.00$ a year to individual members of supporting institutions.

Subscriptions, orders for back numbers, and changes of address should be sent to Pacific Journal of Mathematics, 103 Highland Boulevard, Berkeley, California, 94708.

PUBLISHED BY PACIFIC JOURNAL OF MATHEMATICS, A NON-PROFIT CORPORATION

Printed at Kokusai Bunken Insatsusha (International Academic Printing Co., Ltd.), 270, 3-chome Totsuka-cho, Shinjuku-ku, Tokyo 160, Japan.

* C. R. DePrima California Institute of Technology, Pasadena, CA 91109, will replace J. Dugundji until August 1974.

Copyright (C) 1973 by Pacific Journal of Mathematics

Manufactured and first issued in Japan 


\section{Pacific Journal of Mathematics}

\section{Vol. 51, No. $2 \quad$ December, 1974}

Robert F. V. Anderson, Laplace transform methods in multivariate spectral theory .................................................. 339

William George Bade, Two properties of the Sorgenfrey plane . . . . . . . . . . . . 349

John Robert Baxter and Rafael Van Severen Chacon, Functionals on continuous

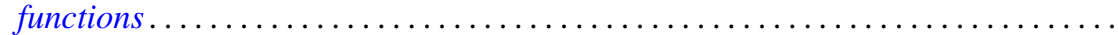

Phillip Wayne Bean, Helly and Radon-type theorems in interval convexity

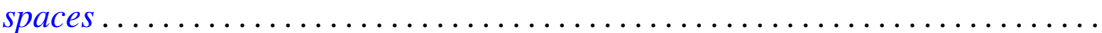

James Robert Boone, On k-quotient mappings $\ldots \ldots \ldots \ldots \ldots \ldots \ldots \ldots \ldots$

Ronald P. Brown, Extended prime spots and quadratic forms . . . . . . . . . . . .

William Hugh Cornish, Crawley's completion of a conditionally upper continuous lattice .............................................

Robert S. Cunningham, On finite left localizations ...................

Robert Jay Daverman, Approximating polyhedra in codimension one spheres

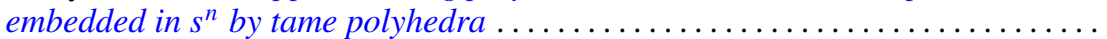

Burton I. Fein, Minimal splitting fields for group representations . . . . . . . . . . . .

Peter Fletcher and Robert Allen McCoy, Conditions under which a connected

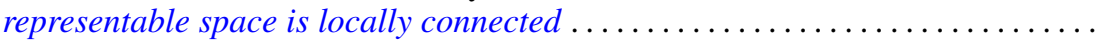

Jonathan Samuel Golan, Topologies on the torsion-theoretic spectrum of a noncommutative ring...

Manfred Gordon and Edward Martin Wilkinson, Determinants of Petrie matrices.

Alfred Peter Hallstrom, A counterexample to a conjecture on an integral condition for determining peak points (counterexample concerning peak points)........

E. R. Heal and Michael Windham, Finitely generated $F$-algebras with applications to Stein manifolds.

Denton Elwood Hewgill, On the eigenvalues of a second order elliptic operator in an unbounded domain ............................

Charles Royal Johnson, The Hadamard product of $A$ and $A^{*}$.

Darrell Conley Kent and Gary Douglas Richardson, Regular completions of Cauchy spaces.

Alan Greenwell Law and Ann L. McKerracher, Sharpened polynomial approximation

Bruce Stephen Lund, Subalgebras of finite codimension in the algebra of analytic functions on a Riemann surface. .

Robert Wilmer Miller, TTF classes and quasi-generators . .

Roberta Mura and Akbar H. Rhemtulla, Solvable groups in which every maximal partial order is isolated ....

Isaac Namioka, Separate continuity and joint continuity...

Alan Saleski, Entropy of self-homeomorphisms of statistical pseudo-metric

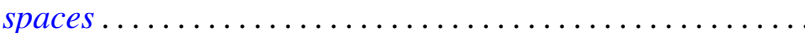

H. A. Seid, Cyclic multiplication operators on $L_{p}$-spaces .....

H. B. Skerry, On matrix maps of entire sequences ............

John Brendan Sullivan, A proof of the finite generation of invariants of a normal

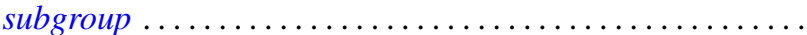

John Griggs Thompson, Nonsolvable finite groups all of whose local subgroups are

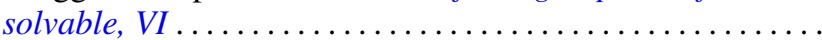

